\title{
Viral causes of Influenza Like IIIness in Uganda, 2008 to 2017.
}

\author{
Derrick E. Mimbe*1, Denis K. Byarugaba², Bernard Erima', Edison Mworozi ${ }^{3}$, \\ Monica Millard'1, Titus Tugume'1, Jocelyn Kiconco', Paska Lamunu', Hannah Kibuuka1 \\ and Fred Wabwire-Mangen ${ }^{3}$
}

${ }^{1}$ Makerere University Walter Reed Project, Kampala, Uganda; ${ }^{2}$ Makerere University College of Veterinary Medicine, Animal Resources and Bio-security, Kampala, Uganda; ${ }^{3}$ Makerere University College of Health Sciences, Kampala, Uganda

\section{Objective}

To determine viral causes of influenza-like illness in Uganda.

\section{Introduction}

Respiratory pathogens continue to present an ever increasing threat to public health $(1,2)$. Influenza, Respiratory syncytial virus, human metapneumovirus and other respiratory viruses are major etiological agents for influenza like illnesses (ILI) (3-5). Establishment of viral causes of ILI is critical for prevention and mitigation strategies to disease threats. Makerere University Walter Reed Project (MUWRP) together with the Ugandan Ministry of Health and partners undertook surveillance to determine viral causes of influenza-like illness in Uganda.

\section{Methods}

From 2008, MUWRP established hospital-based sentinel sites for surveillance activities. A total of five hospital-based sites were established, where patients aged 6 months or older presenting with ILI were enrolled. Consents were obtained as required, and a throat and/ or nasopharyngeal swab collected. Samples were screened by PCR for viral causes.

\section{Results}

From October 2008 to March 2017 a total of 9,472 participants were enrolled in the study from five hospital-based surveillance sentinel sites. Majority of participants were children under 5 years $n=$ $8,169(86.2 \%) .615(6.5 \%)$ samples tested positive for influenza A, while $385(4.1 \%)$ tested positive for influenza B viruses and $10(0.1 \%)$ were co-infections between influenza A and B. Of the 2,062 influenza negative samples, results indicated positivity for the following organisms; adenoviruses $(9.4 \%)$, respiratory syncytial B $(7.3 \%)$, parainfluenza-3 $(4.5 \%)$, parainfluenza-1 $(4.3 \%)$, respiratory syncytial A $(3.5 \%)$, human bocavirus $(1.7 \%)$, human metapneumovirus $(1.7 \%)$, human coronavirus $(1.5 \%)$, parainfluenza-4 $(1.4 \%)$ and parainfluenza-2 $(0.9 \%)$ by PCR.

\section{Conclusions}

Influenza viruses account for about $11 \%$ of the causes of influenza like illness, with influenza A being the dominant type. Among the other viral causes of ILI, adenoviruses were the most dominant. Detection of other viral causes of ILI is an indication of the public health threats posed by respiratory pathogens.

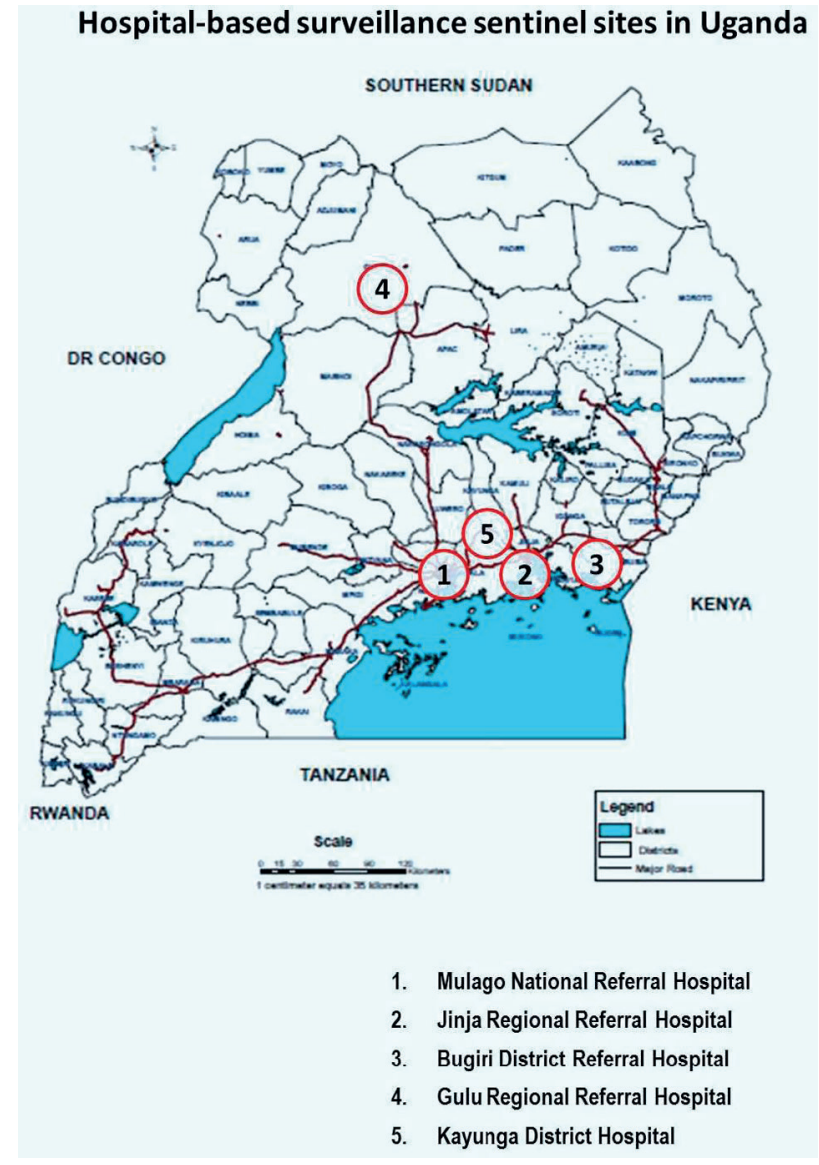

Keywords

Influenza; Influenza Like Illness; Surveillance

\section{Acknowledgments}

The authors would want to acknowledge the project and sentinel surveillance site staff for their contribution and dedication. This study was supported by the US Department of Defence through the Armed Forces Health Surveillance Branch - Global Emerging Infections Surveillance and Response and Henry Jackson Foundation for Advancement of Medicine.

\section{References}

IOM (Institute of Medicine), 2009. Microbial evolution and coadaptation: a tribute to the life and scientific legacies of Joshua Lederberg. Washington, DC: The National Academies Press. 
Horton KC, Dueger EL, Kandeel A, Abdallat M, El-Kholy A, Al-Awaidy S, et al., 2017. Viral etiology, seasonality and severity of hospitalized patients with severe acute respiratory infections in the Eastern Mediterranean Region, 2007-2014. PLoS ONE 2017; 12(7).

Kamigaki T, Aldey PP, Mercado ES, Tan AG, Javier JB, Lupisan SP, Oshitani H, Tallo VL., 2017. Estimates of influenza and respiratory syncytial virus incidences with fraction modeling approach in Baguio City, the Philippines, 2012-2014. Influenza Other Respir Viruses. Jul; 11(4):311-318.

Moe N, Stenseng IH, Krokstad S, Christensen A, Skanke LH, Risnes KR, Nordbo SA, Dollner H., 2017. The Burden of Human Metapneumovirus and Respiratory Syncytial Virus Infections in Hospitalized Norwegian Children. J Infect Dis. Jul 1; 216(1):110-116.

Shapiro D., Bodinayake CK, Nagahawatte A, Devasiri V, Kurukulasooriya R, Hsiang J, Nicholson B6, De Silva AD7, Ostbye T, Reller ME, Woods CW, Tillekeratne LG, 2017. Burden and Seasonality of Viral Acute Respiratory Tract Infections among Outpatients in Southern Sri Lanka. Am J Trop Med Hyg. Jul; 97(1):88-96.

\section{*Derrick E. Mimbe}

E-mail: dmimbe@muwrp.org 